\title{
Effects of maintenance lithium treatment on serum parathyroid hormone and calcium levels: a retrospective longitudinal naturalistic study
}

This article was published in the following Dove Press journal:

Neuropsychiatric Disease and Treatment

20 July 2015

Number of times this article has been viewed

\section{Umberto Albert ${ }^{1}$ \\ David De Cori' \\ Andrea Aguglia' \\ Francesca Barbaro' \\ Fabio Lanfranco ${ }^{2}$ \\ Filippo Bogetto' \\ Giuseppe Maina ${ }^{3}$}

'Anxiety and Mood Disorders Unit, Rita Levi Montalcini Department of Neuroscience, University of Turin, Torino, Italy; ${ }^{2}$ Division of Endocrinology, Diabetology and Metabolism, Department of Medical Sciences, University of Turin, Torino, Italy; ${ }^{3}$ Department of Mental Health, San Luigi-Gonzaga Hospital, University of Turin, Orbassano, Italy
Correspondence: Umberto Albert Anxiety and Mood Disorders Unit, Rita Levi Montalcini Department of Neuroscience, University of Turin, Via Cherasco II, 10126 Torino, Italy Tel +390116335425

Fax +39011673473

Email umberto.albert@unito.it
Objective: The aim of this retrospective longitudinal naturalistic study was to evaluate the effects of maintenance lithium treatment on parathyroid hormone (PTH) and calcium levels.

Methods: A retrospective longitudinal naturalistic study design was used. Data were collected from the database of a tertiary psychiatric center covering the years 2010-2014. Included were bipolar patients who had never been exposed to lithium and had lithium started, and who had PTH, and total and ionized calcium levels available before and during lithium treatment. Paired $t$-tests were used to analyze changes in PTH and calcium levels. Linear regressions were performed, with mean lithium level and duration of lithium exposure as independent variables and change in PTH levels as dependent variable.

Results: A total 31 patients were included. The mean duration of lithium treatment was $18.6 \pm 11.4$ months. PTH levels significantly increased during lithium treatment $(+13.55 \pm 14.20 \mathrm{pg} / \mathrm{mL})$; the rate of hyperparathyroidism was $12.9 \%$. Neither total nor ionized calcium increased from baseline to follow-up; none of our patients developed hypercalcemia. Linear regressions analyses did not show an effect of duration of lithium exposure or mean lithium level on PTH levels.

Conclusion: Lithium-associated stimulation of parathyroid function is more common than assumed to date. Among parameters to be evaluated prior to lithium implementation, calcium and PTH should be added.

Keywords: bipolar disorder, follow-up study, lithium side-effects

\section{Introduction}

Lithium is recommended by all treatment guidelines for bipolar disorder (BD) as a first-line maintenance treatment, and recent trial data have definitely established the efficacy of lithium in the prophylaxis of BD. ${ }^{1-10}$ The clinical benefit of lithium over the long term, however, has to be balanced against the risks that it might confer. The most commonly reported adverse effects associated with long-term lithium treatment are clinical hypothyroidism and reduced urinary concentrating ability. ${ }^{11-13}$

Less attention has been devoted to alterations in calcium metabolism potentially associated with long-term lithium treatment. In case-control studies, lithium treatment is associated with increased blood calcium $(+0.09 \mathrm{mmol} / \mathrm{L})$ and parathyroid hormone (PTH) $(+7.32 \mathrm{pg} / \mathrm{mL}) .{ }^{12}$ Rates of lithium-associated hyperparathyroidism, however, vary enormously between studies, from $2.7 \%$ to $23.2 \%$ and up to $47.8 \%$ in elderly patients. ${ }^{14-19}$ Discrepancies depend on definitions of hyperparathyroidism used and different lengths of exposure to lithium in different samples. Rates of subjects with hypercalcemia also vary considerably across different studies. When total serum 
calcium was measured, rates of hypercalcemia were comprised between $3.6 \%$ (persistent hypercalcemia) and 15.6\%; when ionized calcium was measured, rates increased to $25 \%-42.3 \%{ }^{14,15,20-23}$ In a recent case-control, cross-sectional study, we found that PTH and ionized calcium levels were significantly higher in lithium-exposed patients $(n=58)$ than in subjects never exposed to lithium $(n=54) .{ }^{17}$ Rates of hyperparathyroidism (PTH levels $>65 \mathrm{pg} / \mathrm{mL})(8.6 \%)$ and hypercalcemia (ionized calcium $>1.32 \mathrm{mmol} / \mathrm{L})(24.1 \%)$ were significantly greater in lithium-exposed subjects. ${ }^{17}$

The exact prevalence of lithium-associated alterations in calcium metabolism and the mechanism by which lithium alters serum calcium and PTH levels are to be further determined. Various hypotheses on the underlying mechanism of hyperparathyroidism have been proposed: increased threshold of the calcium-sensing receptor within the parathyroid gland; increase of PTH; decrease of the intracellular calcium uptake; inhibition of action of glycogen synthase kinase $3 \mathrm{~b}$; and reduction of $\mathrm{PTH}$ gene transcription. ${ }^{24}$ Prospective longitudinal studies might add useful information on this topic.

To date, only four studies prospectively assessed serum calcium and/or PTH levels in patients on long-term lithium treatment. ${ }^{25-28}$ Results of these studies are controversial. Aronoff et al evaluated serum calcium levels in 18 patients (14 "manic depressive", mixed unipolar, and bipolar patients, and four schizoaffective patients) before lithium, 1 week after beginning of lithium and 2 months later, and then off lithium: no changes in serum calcium levels were detected. ${ }^{25}$ Nielsen et al found, in ten patients, that PTH increased more than $40 \%$ within the first week on lithium treatment and remained elevated throughout the 3-month treatment period. ${ }^{26}$ No significant changes in serum calcium levels were detected. Christiansen et al enrolled 13 bipolars that had never been treated with any psychopharmacological drugs and followed them up for 3 months; serum PTH, calcium, and magnesium levels were monthly assessed. ${ }^{27}$ During lithium treatment, serum levels of PTH, calcium, and magnesium significantly increased, and this was evident 1 month after institution of lithium therapy. Finally, Mak et al studied 53 patients receiving lithium therapy prospectively for 2 years; patients were mixed bipolar $(n=48)$ and unipolar $(n=5)$ subjects that had not previously been treated with lithium. ${ }^{28}$ Lithium significantly increased serum PTH levels (progressively from $2.8 \pm 1.2 \mathrm{pmol} / \mathrm{L}$ to $3.9 \pm 1.5 \mathrm{pmol} / \mathrm{L}$ after 2 years), while no changes in serum calcium levels were detected. The increase in PTH levels was evident after 1 month from the beginning of the treatment, although the difference became statistically significant only after 6 months. ${ }^{28}$
Prospective longitudinal studies seem to suggest that serum PTH levels do rise on lithium treatment, although the studies do diverge concerning calcium measurements: Christiansen et al found an increase in calcium from the first month, while Aronoff et al, Nielsen et al, and Mak et al did not detect any change in serum calcium levels. ${ }^{25-28}$ Longitudinal studies also differ in identifying the time of occurrence of the increase in PTH levels: In the Nielsen et al study, PTH increased within the first week from lithium institution, while Christiansen et al found a significant increase in PTH levels after 1 month, and in the Mak et al study, an increase was evident after 1 month from beginning of the treatment, although the difference became statistically significant only after 6 months. ${ }^{26-28}$

Finally, when lithium therapy is stopped, both blood calcium and PTH normalize within several months. If hypercalcemia persists after withdrawal of lithium, decisions about surgery follow the same guidelines as those for patients with primary hyperparathyroidism. ${ }^{29}$

Hyperparathyroidism is associated with increased admissions for nonfatal cardiovascular disease, renal failure, renal stones, fractures, hypertension, cancer, and diabetes; the investigation of long-term consequences of lithium on parathyroid function is then relevant for clinical practice.

The aim of the present retrospective longitudinal study was to compare serum PTH and calcium levels in lithium-exposed bipolar patients before and after lithium institution.

\section{Material and methods Subjects}

A retrospective, longitudinal, naturalistic study design was used. The data were retrieved from the database of the Anxiety and Mood Disorder Unit, Department of Neuroscience of the University of Turin (Italy), examining patients referred between January 2010 and July 2014. Included in the study were patients (in- and outpatients) with a primary diagnosis of Diagnostic and Statistical Manual of Mental Disorders Version 4 (DSM-IV) Bipolar Disorder I or II ${ }^{30}$ (made by psychiatrists with the Structured Clinical Interview for DSM-IV-TR Axis I Disorders [SCID-I/P] ${ }^{31}$ ). Inclusion criteria were: 1) at least 18 years of age; 2) patients had to have never been exposed to lithium before; 3 ) and had to have started lithium, with a lithium blood level checked at least 5 days after lithium reached the target oral dose. The electronic medical files (for inpatients) and the medical charts (for outpatients) were reviewed for clinical data and for changes in PTH levels, and serum total and ionized calcium levels; thyroid stimulating hormone (TSH), triiodothyronine (T3) 
and thyroxine (T4), creatinine, urea, sodium, and potassium levels were also examined. When possible, magnesium and phosphate levels were also retrieved. A baseline diagnosis of renal failure, serum creatinine value $>1.5 \mathrm{mg} / \mathrm{dL}$, use of diuretics or medications known to impair vitamin D metabolism, and/or preexisting disorders of calcium homeostasis were considered exclusion criteria. The Ethics Committee of the San Giovanni Battista University Hospital approved the study design.

\section{Assessments and procedures}

All bipolar subjects referred to our unit (inpatients or outpatients) are examined at their first visit with a semistructured interview, with a format that covers the following areas: a) sociodemographic data; b) diagnoses (current and lifetime) provided by clinicians with at least 4 years of postgraduate clinical experience, by means of the SCID-I/P; ${ }^{32}$ c) clinical data (such as type of BD, age at onset of first-ever mood episode, and total number of episodes); d) the Young Mania Rating Scale (YMRS), ${ }^{33}$ 17-item Hamilton Depression Rating Scale (HAM-D), ${ }^{34}$ Hamilton Anxiety Rating Scale (HAM-A), ${ }^{35}$ and Clinical Global Impression Scale-Severity of Illness. ${ }^{36}$ Use of medications at the time of interview is also recorded; moreover, lifetime exposure to mood stabilizers is recorded by means of direct interview, family members' interview (when available), and medical records review.

A blood draw for routine blood exam is performed at hospital admission for inpatients, as a part of the clinical management routine. For outpatients, patients are scheduled for a blood test within a week from the study visit. At the time when blood is drawn, patients have been fasting for the previous 10 hours. Blood exams include complete blood count, PTH, total and ionized calcium, TSH, T3 and T4, creatinine, urea, sodium and potassium, and lithium serum levels. For the purposes of the present study, we recorded these data as baseline data (before initiation of lithium treatment).

In addition, for most patients who are regularly followed at our unit as outpatients, we monitor PTH, calcium, TSH, creatinine, urea, electrolytes, and plasma lithium levels every 3-6 months (according to International Society for Bipolar Disorders [ISBD] clinical guidelines). ${ }^{37}$ For the purposes of the present study, we recorded the last available blood tests taken during follow-up; these data, taken when patients were on a stable maintenance lithium dose, were defined as the end point.

Exposure to lithium was calculated as mean lithium level $(\mathrm{mmol} / \mathrm{L})$ in the follow-up period for each patient; all lithium levels recorded in the hospital databases during these retrospective periods were used to compute the mean lithium level. Duration of lithium exposure in months was also computed for each patient.

\section{Statistical analysis}

Primary outcome measures were changes in PTH levels, and total and ionized calcium, between baseline (off lithium or before lithium institution) and end of study (end of follow-up on lithium). The secondary outcome measures were changes in TSH, creatinine, urea, sodium, potassium, magnesium and phosphate levels between baseline and follow-up. Paired $t$-tests were used to analyze changes in primary and secondary outcome variables. Lastly, linear regressions were performed, with mean lithium level and duration of lithium exposure as the main independent variables and change in PTH levels as the dependent variable.

\section{Results}

Of approximately 500 charts screened, 34 bipolar patients had lithium instituted for the first time ever and had at least another blood test taken with serum PTH and calcium levels during follow-up; of these, three subjects were excluded because of hyperparathyroidism (PTH $>65 \mathrm{pg} / \mathrm{mL}$ ) at baseline, due in all cases to $25 \mathrm{OH}$-vitamin D levels $<20 \mathrm{ng} / \mathrm{mL}$. A total 31 patients constituted our sample. The mean duration of lithium treatment (mean length of follow-up) was 18.6 \pm 11.4 months (range 6-48 months). The mean lithium oral dose at end of follow-up was $720.8 \pm 227.2 \mathrm{mg} /$ day, and mean plasma lithium level during the follow-up period was $0.66 \pm 0.12$ $\mathrm{mmol} / \mathrm{L}$. Sociodemographic and clinical characteristics of patients included at baseline are reported in Table 1.

Changes in parameters related to calcium metabolism are reported in Table 2. A significant increase was only reported for PTH levels (mean increase of $13.55 \pm 14.20 \mathrm{pg} / \mathrm{mL}$ ). Five (16.1\%) patients developed hyperparathyroidism (PTH levels $>65 \mathrm{pg} / \mathrm{mL}$ ) during the follow-up; of these, one had $25 \mathrm{OH}$-vitamin D levels $<20 \mathrm{ng} / \mathrm{mL}$, and once vitamin D was supplemented, PTH levels returned within the normal range. The rate of lithium-associated hyperparathyroidism in our sample was then $12.9 \%$ (4/31 subjects). Of note, PTH levels increased without a parallel increase in calcium (total or ionized) levels (mean increase in total calcium was $0.03 \pm 0.11 \mathrm{mmol} / \mathrm{L}$; the mean change in ionized calcium was $-0.01 \pm 0.1 \mathrm{mmol} / \mathrm{L})$.

Table 3 shows changes in thyroid and renal function parameters during the 18.6 month follow-up period. No statistically significant changes were found in thyroid and renal function parameters except for an increase, from baseline to follow-up, in TSH levels. The proportion of patients with 
Table I Sociodemographic and clinical characteristics of the included patients

\begin{tabular}{|c|c|}
\hline & $\begin{array}{l}\text { Patients never exposed } \\
\text { to lithium }(\mathrm{N}=3 \mathrm{I})\end{array}$ \\
\hline Actual age (years), mean $\pm S D$ & $48.4 \pm 15.2$ \\
\hline Sex (male), n (\%) & $12(38.7)$ \\
\hline Educational level (years), mean \pm SD & $12.8 \pm 4.6$ \\
\hline \multicolumn{2}{|l|}{ Marital status, $\mathrm{n}(\%)$} \\
\hline Married & $17(54.8)$ \\
\hline Divorced & $2(6.5)$ \\
\hline Never married & II (35.5) \\
\hline Widowed & I (3.2) \\
\hline Currently working, n (\%) & $17(54.8)$ \\
\hline \multicolumn{2}{|l|}{ Bipolar disorder, n (\%) } \\
\hline Type I & $19(61.3)$ \\
\hline Type II & $12(38.7)$ \\
\hline Age at onset (years), mean \pm SD & $27.6 \pm 8.9$ \\
\hline Total number of episodes, mean \pm SD & $7.6 \pm 5.3$ \\
\hline Duration of illness (years), mean $\pm S D$ & $21.8 \pm 12.5$ \\
\hline $\begin{array}{l}\text { Lithium mean dose (mg/day), mean } \pm S D \\
\text { (min-max) }\end{array}$ & $720.8 \pm 227.2(300-1200)$ \\
\hline Blood lithium levels (mmol/L), mean \pm SD & $0.66 \pm 0.12$ \\
\hline $\begin{array}{l}\text { Length of follow-up (months), mean } \pm S D \\
\text { (min-max) }\end{array}$ & $|8.6 \pm| \mid .4(6-48)$ \\
\hline $\mathrm{BMI}$, mean $\pm \mathrm{SD}$ & $25.9 \pm 5.1$ \\
\hline
\end{tabular}

Abbreviations: BMI, body mass index; max, maximum; min, minimum.

clinical hypothyroidism (patients with replacement therapy or TSH $>4.2 \mu \mathrm{IU} / \mathrm{mL}$ and free $\mathrm{T} 3<2.6 \mathrm{pg} / \mathrm{mL}$ ) increased also, from $3.2 \%$ to $12.9 \%$ at the end of follow-up. Body mass index (BMI) did not change during lithium treatment.

Linear regression analyses did not show an effect of either mean lithium level (analysis of variance [ANOVA]: $F=0.194$, $P=0.663$ ) or duration of lithium exposure (ANOVA: $F=0.451$, $P=0.507)$ on changes in serum PTH levels.

\section{Discussion}

Our retrospective longitudinal study confirmed that maintenance lithium treatment is associated with a significant increase in serum PTH levels: The mean increase found in the present study was $13.5 \mathrm{pg} / \mathrm{mL}$ during an 18 -month follow-up period. Long-term lithium treatment was also associated with hyperparathyroidism: A total $12.9 \%$ of bipolar subjects never exposed to this compound before showed, during the follow-up, PTH levels $>65 \mathrm{pg} / \mathrm{mL}$. This rate of hyperparathyroidism is even higher than what we described in a previous study. ${ }^{17}$ Interestingly, neither total calcium nor ionized calcium levels increased during lithium treatment in our cohort. We have previously described an increase in PTH and ionized calcium levels in a group of 58 patients in continuous lithium treatment, in line with other literature data highlighting an association between hypercalcemia and lithium therapy. ${ }^{17}$ Magnesium and phosphate levels also did not change during follow-up.

Our results are in line with those of the previous longitudinal studies performed to date. Serum PTH levels were found to rise during lithium treatment. ${ }^{26-28}$ Concerning calcium levels, the majority of the prospective studies did not detect any change in serum calcium levels, while only Christiansen et al found an increase in calcium. ${ }^{25-28}$ Longitudinal studies, then, do suggest that the effect of lithium on calcium homeostasis is primarily mediated through an increase in PTH levels; the lack of any significant change in the serum calcium level indicates that for any given level of calcium, the PTH concentration is higher during stable lithium therapy. Lithium-associated hyperparathyroidism, then, appears to be independent of calcium levels. In the present study,

Table 2 Serum PTH and calcium levels at first (basal) and last (end point) measurements

\begin{tabular}{|c|c|c|c|c|}
\hline & \multirow{2}{*}{$\begin{array}{l}\begin{array}{l}\text { Baseline } \\
\text { (off lithium) }\end{array} \\
\mathbf{N}=3 \text { I }\end{array}$} & \multirow{2}{*}{$\begin{array}{l}\begin{array}{l}\text { Follow-up } \\
\text { (on lithium) }\end{array} \\
\mathrm{N}=31\end{array}$} & \multicolumn{2}{|c|}{ Paired $t$-test } \\
\hline & & & $\boldsymbol{t}$ & $P$-values \\
\hline $\begin{array}{l}\text { PTH }(\mathrm{pg} / \mathrm{mL}) \text {, mean } \pm \text { SD } \\
\text { Normal range: } 15-65 \mathrm{pg} / \mathrm{mL}\end{array}$ & $34.90 \pm 11.63$ & $48.45 \pm 15.83$ & -5.313 & $<0.001$ \\
\hline Hyperparathyroidism, n (\%)* & $0(0)$ & $5(16.1)$ & - & - \\
\hline $\begin{array}{l}\text { Total calcium (mmol/L), mean } \pm \text { SD } \\
\text { Normal range: } 2.20-2.60 \mathrm{mmol} / \mathrm{L}\end{array}$ & $2.32 \pm 0.09$ & $2.36 \pm 0.08$ & $-1.57 \mid$ & 0.127 \\
\hline Hypercalcemia, n (\%)** & $0(0)$ & $0(0)$ & - & - \\
\hline $\begin{array}{l}\text { lonized calcium }(\mathrm{mmol} / \mathrm{L}) \text {, mean } \pm S D \\
\text { Normal range: } 1.10-1.32 \mathrm{mmol} / \mathrm{L}\end{array}$ & $1.13 \pm 0.10$ & $1.12 \pm 0.07$ & 0.420 & 0.677 \\
\hline Hypercalcemia, n (\%) ${ }^{\dagger}$ & $\mathrm{I}(3.2)$ & $0(0)$ & - & - \\
\hline $\begin{array}{l}\text { Magnesium (mmol/L), mean } \pm \text { SD } \\
\text { Normal range: } 0.62-1.06 \mathrm{mmol} / \mathrm{L}\end{array}$ & $0.88 \pm 0.17$ & $0.84 \pm 0.10$ & 0.954 & 0.348 \\
\hline $\begin{array}{l}\text { Phosphate (mmol/L), mean } \pm \mathrm{SD} \\
\text { Normal range: } 0.8 \mathrm{I}-\mathrm{I} .45 \mathrm{mmol} / \mathrm{L}\end{array}$ & $1.04 \pm 0.22$ & $1.01 \pm 0.12$ & 0.684 & 0.499 \\
\hline
\end{tabular}

Notes: *Defined as PTH $>65 \mathrm{pg} / \mathrm{mL}$. **Defined as total calcium $>2.60 \mathrm{mmol} / \mathrm{L}$. ${ }^{\dagger}$ Defined as ionized calcium $>1.32 \mathrm{mmol} / \mathrm{L}$. Abbreviation: PTH, parathyroid hormone. 
Table 3 Thyroid and renal function parameters at first (basal) and last (end point) measurements

\begin{tabular}{|c|c|c|c|c|}
\hline & \multirow{2}{*}{$\begin{array}{l}\begin{array}{l}\text { Baseline } \\
\text { (off lithium) }\end{array} \\
\mathbf{N}=3 \text { I }\end{array}$} & \multirow{2}{*}{$\begin{array}{l}\text { Follow-up } \\
\text { (on lithium) } \\
\mathrm{N}=3 \mathrm{I}\end{array}$} & \multicolumn{2}{|c|}{ Paired $t$-test } \\
\hline & & & $t$ & $P$-values \\
\hline Clinical hypothyroidism, n (\%)* & $\mathrm{I}(3.2)$ & $4(12.9)$ & - & - \\
\hline $\begin{array}{l}\text { TSH }(\mu \mathrm{IU} / \mathrm{L}) \text {, mean } \pm \mathrm{SD} \\
\quad \text { Normal range: } 0.27-4.2 \mu \mathrm{IU} / \mathrm{mL}\end{array}$ & $1.95 \pm 1.41$ & $2.6 I \pm 1.50$ & -2.040 & 0.050 \\
\hline $\begin{array}{l}\text { Creatinine }(\mathrm{mg} / \mathrm{dL}), \text { mean } \pm \mathrm{SD} \\
\text { Normal range: } 0.5-1.5 \mathrm{mg} / \mathrm{dL}\end{array}$ & $0.79 \pm 0.16$ & $0.82 \pm 0.17$ & -1.443 & 0.159 \\
\hline $\begin{array}{l}\text { Urea }(\mathrm{mg} / \mathrm{dL}) \text {, mean } \pm S D \\
\text { Normal range: } 10-50 \mathrm{mg} / \mathrm{dL}\end{array}$ & $29.84 \pm 8.43$ & $27.06 \pm 7.9$ & 2.002 & 0.054 \\
\hline $\begin{array}{l}\text { Sodium (mmol/L), mean } \pm \mathrm{SD} \\
\text { Normal range: } 135-145 \mathrm{mmol} / \mathrm{L}\end{array}$ & $14 \mid .3 \pm 2.5$ & $140.7 \pm 2.8$ & 0.950 & 0.350 \\
\hline $\begin{array}{l}\text { Potassium (mmol/L), mean } \pm \mathrm{SD} \\
\text { Normal range: } 3.5-5.0 \mathrm{mmol} / \mathrm{L}\end{array}$ & $4.09 \pm 0.31$ & $4.18 \pm 0.25$ & -1.485 & 0.148 \\
\hline $\mathrm{BMI}$, mean $\pm \mathrm{SD}$ & $25.98 \pm 5.08$ & $25.66 \pm 4.93$ & 0.779 & 0.442 \\
\hline Psoriasis, n (\%)** & $0(0)$ & I (3.2) & - & - \\
\hline
\end{tabular}

Notes: *Patients with replacement therapy or TSH $>4.2 \mu \mathrm{IU} / \mathrm{mL}$ and $\mathrm{FT} 3<2.6 \mathrm{pg} / \mathrm{mL}$. **Clinical diagnosis made by dermatologist.

Abbreviations: BMI, body max index; FT3, free triiodothyronine; TSH, thyroid stimulating hormone.

calcium levels did not change over an 18-month follow-up period and hypercalcemia rates were $<5 \%$, consistent with recent studies using relatively stringent (and clinically useful) definitions for clinical hypercalcemia. ${ }^{18,38,39}$ Our study, moreover, adds to previous findings demonstrating that, also, post-lithium phosphate levels do not differ from pre-lithium levels. ${ }^{26-28}$

It is still unclear whether lithium initiates the disease or uncovers an underlying state of hyperparathyroidism. Putative mediating mechanisms include the induction of parathyroid hyperplasia and/or adenomas; ${ }^{15,40}$ interference with the negative feedback loop for parathyroid hormone secretion, through altering the threshold of calcium-sensing receptors; ${ }^{15,41}$ and inhibition of glycogen synthase kinase $3 b{ }^{42}$

Our results clearly show that lithium treatment may affect calcium metabolism, although the proportion of patients with overt hyperparathyroidism is low. What are the implications for clinical practice? Patients who developed lithiumassociated hyperparathyroidism, in our cohort, did not show any signs or symptoms, having total and ionized calcium levels within the normal ranges. Normocalcemic primary hyperparathyroidism is a well-documented nosographic entity and is related to reduced bone density. ${ }^{43}$ Lithium treatment for bipolar disorder is usually lifelong; continuously elevated PTH levels, even with normal calcium levels, can thus lead to reduced bone mineral density, osteoporosis and increased fracture risk. Moreover, older patients and patients with comorbid renal disease may be especially vulnerable to developing symptomatic hypercalcemia and hyperparathyroidism requiring treatment. ${ }^{44}$ The consequences in term of reduced mobilization, disability, and health care costs have to be balanced against the cost of PTH measurements.

The question of whether clinicians should avoid lithium in patients with preexisting hypercalcemia/hyperparathyroidism is an important one for future studies to ascertain. It is probably premature to state that this is the case at the current time. In the case of lithium use in patients with renal failure, for example, it is still advisable to continue lithium most of the time, when carefully weighing the pros and cons of this medication. ${ }^{45}$ It is possible that future studies will give us clinically meaningful indications about prescribing lithium in subjects at risk for hypercalcemia/hyperparathyroidism. As clinicians, however, we have to counterbalance the risks associated with the use of a specific drug (eg, lithium) versus benefits of its long-term use and risks associated with its discontinuation. For lithium, there is a clear demonstration that rapid discontinuation of its use is associated with affective relapses. ${ }^{11}$

This study has several limitations. First of all, there was no control group. Moreover, the size of the sample was small. However, the strength of our study is in the selection of a group of patients never exposed to lithium before, for which we could examine PTH and calcium levels (both total and ionized calcium) at baseline (before lithium institution) and at follow-up (on stable lithium treatment). The relatively longterm follow-up (mean 18.6 months) is another strength of the present study; previous longitudinal studies followed patients for 2 months ${ }^{25}$ or 3 months, ${ }^{26}$ and only Mak et al had a longer follow-up (24 months).$^{28}$ Our results need to be confirmed in greater samples prospectively followed up. 
What remains to be further determined is a) which patients are more prone to develop lithium-associated alterations in calcium homeostasis and b) whether longer exposures to lithium (years) will end in hypercalcemia and then symptomatic hyperparathyroidism. In our study, we failed to show a relationship between the duration of exposure to lithium or the mean plasma level of lithium and PTH levels. We can conclude, then, that lithium exposes subjects at a higher risk of an increase in PTH levels and overt hyperparathyroidism but that we still don't know which patients are particularly vulnerable.

\section{Conclusion}

In conclusion, our study shows that lithium does raise PTH levels without altering calcium levels. However, despite results of the studies pointing to an association between lithium treatment and hyperparathyroidism, serum calcium monitoring is not included in the most recent National Institute for Health and Care Excellence (NICE) and American Psychiatric 1 Association (APA) guidelines for the management of patients with BD on long-term lithium therapy. ${ }^{1,2}$ Only the ISBD recommends the addition of calcium (but not PTH levels) to the baseline battery of investigations when treatment with lithium is planned. ${ }^{9,37}$ Repeating serum calcium at 6 months and then annually is also recommended. ${ }^{37}$ As a consequence, serum calcium and PTH remain poorly monitored in patients on long-term lithium treatment in clinical practice. Lally et al assessed the extent of screening for calcium dysfunction in a cohort of individuals on long term lithium therapy who were monitored by their general practitioners over a 2 -year period and found that $14.4 \%$ of 333 patients did not have a serum calcium level measured over this period. ${ }^{38}$ The measurement of PTH was only performed in a third of patients with a raised calcium level (5.3\% was the prevalence of hypercalcemia).

Clinicians should be aware of the efficacy of lithium in the prophylaxis of $\mathrm{BD}$ but also of the potential adverse effects associated with long-term lithium use, including hyperparathyroidism. The evaluation of serum PTH and calcium level should be added to baseline blood tests before lithium implementation and during long-term lithium maintenance. ${ }^{46}$ Moreover, it seems prudent to avoid lithium therapy in patients with preexisting hypercalcemia, although this remains to be further investigated. Routine screening evaluation of PTH levels has not been considered necessary until after abnormalities in calcium have been documented. ${ }^{47}$ However, given the results of our study showing a more frequent finding of elevated PTH levels in comparison with serum calcium concentrations, we speculate that monitoring PTH rather than calcium level in lithium-treated patients should be advised. In fact, inappropriately high serum concentration of PTH sustains excessive renal calcium reabsorption, phosphaturia, and $1,25(\mathrm{OH})_{2} \mathrm{D}$ synthesis, as well as increased bone resorption.

\section{Disclosure}

The authors report no conflicts of interest in this work.

\section{References}

1. American Psychiatric Association. Practice guideline for the treatment of patients with bipolar disorder (revision). Am J Psychiatry. 2002;159 (4 Suppl):S1-S50.

2. National Collaborating Centre for Mental Health (UK). Bipolar Disorder: the Management of Bipolar Disorder in Adults, Children and Adolescents, in Primary and Secondary Care. Leicester: National Institute for Health and Clinical Excellence; 2006.

3. Goodwin GM; Consensus Group of the British Association for Psychopharmacology. Evidence-based guidelines for treating bipolar disorder: revised second edition - recommendations from the British Association for Psychopharmacology. J Psychopharmacol. 2009;23(4):346-388.

4. Grunze H, Kasper S, Goodwin G, Bowden C, Möller HJ; WFSBP Task Force on Treatment Guidelines for Bipolar Disorders. The World Federation of Societies of Biological Psychiatry (WFSBP) guidelines for the biological treatment of bipolar disorders, part III: maintenance treatment. World J Biol Psychiatry. 2004;5(3):120-135.

5. Grunze H, Vieta E, Goodwin GM, et al. The World Federation of Societies of Biological Psychiatry (WFSBP) guidelines for the biological treatment of bipolar disorders: update 2009 on the treatment of acute mania. World J Biol Psychiatry. 2009;10(2):85-116.

6. Yatham LN, Kennedy SH, O'Donovan C, et al; Canadian Network for Mood and Anxiety Treatments. Canadian Network for Mood and Anxiety Treatments (CANMAT) guidelines for the management of patients with bipolar disorder: consensus and controversies. Bipolar Disord. 2005;7 Suppl 3:S5-S69.

7. Yatham LN, Kennedy SH, O'Donovan C, et al; Guidelines Group, CANMAT. Canadian Network for Mood and Anxiety Treatments (CANMAT) guidelines for the management of patients with bipolar disorder: update 2007. Bipolar Disord. 2006;8(6):721-739.

8. Yatham LN, Kennedy SH, Schaffer A, et al. Canadian Network for Mood and Anxiety Treatments (CANMAT) and International Society for Bipolar Disorders (ISBD) collaborative update of CANMAT guidelines for the management of patients with bipolar disorder: update 2009. Bipolar Disord. 2009;11(3):225-255.

9. Yatham LN, Kennedy SH, Parikh SV, et al. Canadian Network for Mood and Anxiety Treatments (CANMAT) and International Society for Bipolar Disorders (ISBD) collaborative update of CANMAT guidelines for the management of patients with bipolar disorder: update 2013. Bipolar Disord. 2013;15(1):1-44.

10. Geddes JR, Goodwin GM, Rendell J, et al; BALANCE Investigators and Collaborators. Lithium plus valproate combination therapy versus monotherapy for relapse prevention in bipolar I disorder (BALANCE): a randomised open-label trial. Lancet. 2010;375(9712):385-395.

11. Malhi GS, Tanious M, Das P, Berk M. The science and practice of lithium therapy. Aust N Z J Psychiatry. 2012;46(3):192-211.

12. McKnight RF, Adida M, Budge K, Stockton S, Goodwin GM, Geddes JR. Lithium toxicity profile: a systematic review and meta-analysis. Lancet. 2012;379(9817):721-728.

13. Albert U, De Cori D, Blengino G, Bogetto F, Maina G. [Lithium treatment and potential long-term side effects: a systematic review of the literature]. Riv Psichiatr. 2014;49(1):12-21. Italian. 
14. Kallner G, Petterson U. Renal, thyroid and parathyroid function during lithium treatment: laboratory tests in 207 people treated for 1-30 years. Acta Psychiatr Scand. 1995;91(1):48-51.

15. Bendz H, Sjödin I, Toss G, Berglund K. Hyperparathyroidism and long-term lithium therapy - a cross-sectional study and the effect of lithium withdrawal. J Intern Med. 1996;240(6):357-365.

16. Kusalic M, Engelsmann F. Effect of lithium maintenance therapy on thyroid and parathyroid function. J Psychiatry Neurosci. 1999;24(3):227-233.

17. Albert U, De Cori D, Aguglia A, et al. Lithium-associated hyperparathyroidism and hypercalcaemia: a case-control cross-sectional study. J Affect Disord. 2013;151(2):786-790.

18. van Melick EJ, Wilting I, Ziere G, Kok RM, Egberts TC. The influence of lithium on calcium homeostasis in older patients in daily clinical practice. Int J Geriatr Psychiatry. 2014;29(6):594-601.

19. Oliveira TC, Campos Neto IA, Aguiar-Oliveira MH, Pereira Fde A. Evaluation of parathyroid function and mineral metabolism in psychiatric patients using lithium salts. Arq Bras Endocrinol Metabol. 2014;58(6):619-624.

20. Colt EW, Kimbrell D, Fieve RR. Renal impairment, hypercalcemia, and lithium therapy. Am J Psychiatry. 1981;138(1):106-108.

21. Toffaletti J, McComb RB, Bowers GN. Increase in dialyzable calcium associated with therapy with lithium. Clin Chem. 1979; 25(10):1806-1809.

22. Nordenström J, Elvius M, Bågedahl-Strindlund M, Zhao B, Törring O. Biochemical hyperparathyroidism and bone mineral status in patients treated long-term with lithium. Metabolism. 1994;43(12):1563-1567.

23. Twigt BA, Houweling BM, Vriens MR, et al. Hypercalcemia in patients with bipolar disorder treated with lithium: a cross-sectional study. Int J Bipolar Disord. 2013;1:18.

24. Szalat A, Mazeh H, Freund HR. Lithium-associated hyperparathyroidism: report of four cases and review of the literature. Eur J Endocrinol. 2009;160(2):317-323.

25. Aronoff MS, Evens RG, Durell J. Effect of lithium salts on electrolyte metabolism. J Psychiat Res. 1971;8(2):139-159.

26. Nielsen JL, Christensen MS, Pedersen EB, Darling S, Amdisen A. Parathyroid hormone in serum during lithium therapy. Scand J Clin Lab Invest. 1977;37(4):369-372.

27. Christiansen C, Baastrup PC, Transbøl I. Development of 'primary' hyperparathyroidism during lithium therapy: longitudinal study. Neuropsychobiology. 1980;6(5):280-283.

28. Mak TW, Shek CC, Chow CC, Wing YK, Lee S. Effects of lithium therapy on bone mineral metabolism: a two-year prospective longitudinal study. J Clin Endocrinol Metab. 1998;83(11):3857-3859.

29. Bilezikian JP, Khan AA, Potts JT; Third International Workshop on the Management of Asymptomatic Primary Hyperthyroidism. Guidelines for the management of asymptomatic primary hyperparathyroidism: summary statement from the third international workshop. J Clin Endocrinol Metab. 2009;94(2):335-339.

30. American Psychiatric Association. Diagnostic and Statistic Manual of Mental Disorders. 4th ed. Text revised (DSM-IV-TR). Washington, DC: APA; 1994
31. First MB, Spitzer RL, Gibbon M, Williams JBW, editors. Structured Clinical Interview for DSM-IV-TR Axis I Disorders, Research Version, Patient Edition (SCID-I/P). New York (NY): Biometrics Research, New York State Psychiatric Institute; 2002.

32. Spitzer RL, Williams JBW, Gibbon M. Structured Clinical Interview for DSM-IV (SCID). NewYork State: Biometric Research; 1995.

33. Young R, Biggs J, Ziegler V, Meyer D. A rating scale for mania: reliability, validity and sensitivity. Br J Psychiatry. 1978;133(5):429-435.

34. Hamilton M. A rating scale for depression. J Neurol Neurosurg Psychiatry. 1960;23:56-62.

35. Hamilton M. The assessment of anxiety states by rating. Br JMed Psychol. 1959;32(1):50-55.

36. Guy W, editor. ECDEU Assessment Manual for Psychopharmacology. Rockville, MD: US Department of Heath, Education, and Welfare Public Health Service Alcohol, Drug Abuse, and Mental Health Administration, 1976.

37. Ng F, Mammen OK, Wilting I, et al; International Society for Bipolar Disorders. The International Society for Bipolar Disorders (ISBD) consensus guidelines for the safety monitoring of bipolar disorder treatments. Bipolar Disord. 2009;11(6):559-595.

38. Lally J, Lee B, McDonald C. Prevalence of hypercalcaemia in patients on maintenance lithium therapy monitored in primary care. Ir Med J. 2013;106(1):15-17.

39. Rej S, Segal M, Low NC, et al. In this correspondence, preliminary data in 100 lithium users found that urine osmolality correlated with chronic kidney disease, diabetes mellitus, and hypothyroidism. We hypothesize that GSK-3 $\beta$ inhibition is a potential mechanism for lithium-associated medical illness. Med Hypotheses. 2015;84(6):602.

40. Awad SS, Miskulin J, Thompson N. Parathyroid adenomas versus four-gland hyperplasia as the cause of primary hyperparathyroidism in patients with prolonged lithium therapy. World J Surg. $2003 ; 27(4): 486-488$.

41. Haden ST, Stoll AL, McCormick S, Scott J, Fuleihan G el-H. Alterations in parathyroid dynamics in lithium-treated subjects. J Clin Endocrinol Metab. 1997;82(9):2844-2848.

42. Lienert D, Rege S. Moans, stones, groans, bones and psychiatric overtones: lithium-induced hyperparathyroidism. Aust $N$ Z J Psychiatry. 2008;42(2):171-173.

43. Díaz-Soto G, Julián MT, Puig-Domingo M. Normocalcemic primary hyperparathyroidism: a newly emerging disease needing therapeutic intervention. Hormones (Athens). 2012;11(4):390-396.

44. Lehmann SW, Lee J. Lithium-associated hypercalcemia and hyperparathyroidism in the elderly: what do we know? J Affect Disord. 2013;146(2):151-157.

45. Werneke U, Ott M, Renberg ES, Taylor D, Stegmayr B. A decision analysis of long-term lithium treatment and the risk of renal failure. Acta Psychiatr Scand. 2012;126(3):186-197.

46. Shapiro HI, Davis KA. Hypercalcemia and "primary" hyperparathyroidism during lithium therapy. Am J Psychiatry. 2015;172(1):12-15.

47. Mallette LE, Eichhorn E. Effects of lithium carbonate on human calcium metabolism. Arch Intern Med. 1986;146(4):770-776.
Neuropsychiatric Disease and Treatment

\section{Publish your work in this journal}

Neuropsychiatric Disease and Treatment is an international, peerreviewed journal of clinical therapeutics and pharmacology focusing on concise rapid reporting of clinical or pre-clinical studies on a range of neuropsychiatric and neurological disorders. This journal is indexed on PubMed Central, the 'PsycINFO' database and CAS,

\section{Dovepress}

and is the official journal of The International Neuropsychiatric Association (INA). The manuscript management system is completely online and includes a very quick and fair peer-review system, which is all easy to use. Visit http://www.dovepress.com/testimonials.php to read real quotes from published authors. 